\title{
VERIFYING THE PREDICTION RESULT RELIABILITY USING K-E, EDDY DISSIPATION AND DISCRETE TRANSFER MODELS APPLIED ON METHANE COMBUSTION USING A PROTOTYPE LOW-PRESSURE BURNER
}

\author{
Stanislav Honus ${ }^{1,2}$, Václav Pospíšilík², Simona Jursová' , Zdeněk Šmída², Vieroslav Molnár ${ }^{3}$, \\ Miroslav Dovica ${ }^{3}$ \\ 1 VŠB - Technical University of Ostrava, Centre ENET, 17. listopadu 15, 708 33 Ostrava - Poruba, Czech Republic, \\ e-mail: stanislav.honus@vsb.cz, simona.jursova@vsb.cz \\ 2 VŠB -Technical University of Ostrava, Faculty of Mechanical Engineering, Department of Energy Engineering, \\ 17. listopadu 15, 70833 Ostrava - Poruba, Czech Republic, e-mail: vaclav.pospisilik@vsb.cz, zdenek.smida@ \\ vsb.cz \\ 3 Technical University of Košice, Letná 9, 042 00, Košice, Slovak Republic, e-mail: vierolva.molnar@tuke.sk, \\ miroslav.dovica@tuke.sk
}

Received: 2017.10.05

Accepted: 2017.11.01

Published: 2017.12.05

\begin{abstract}
The article aims to verify the accuracy of a method to simulate the combustion chamber with a low-pressure prototype burner equipped with a specific "mixing element" and air baffle. The burner has an output of $4 \mathrm{~kW}$ and combusts methane. In detail, the article evaluates the accuracy of the final courses of temperatures and $\mathrm{CO}$ concentrations in the combustion chamber, which were obtained having combined the mathematical models k- $\varepsilon$, Eddy Dissipation and Discrete Transfer. CFD software CFX was used for the solution and visualisation of the results. The verification measurements imply that the final course of temperature plotted on the vertical axis of the combustion chamber differs from the real course by $+21.7 \%$ on average. The predicted $\mathrm{CO}$ concentrations are relatively satisfactory in the chamber locations with lower temperatures - at the combustion chamber outlet the deviation from the measured value was $+31.8 \%$. Overall, the applied method may be considered acceptable to simulate the thermal field in a combustion chamber with the described burner.
\end{abstract}

Keywords: burner, combustion, mathematical modeling, verification.

\section{INTRODUCTION}

Mathematical modelling is highly topical and it is used for simulation of solids (e.g. [1-4]) and also continuum (e.g. $[5,6])$. The continuum is often simulated using the so-called Computational Fluid Dynamics (CFD) method. CFD has been more widely applied to simulate flows as it allows the inclusion of e.g. turbulence, chemical reactions or heat transfer. The results are frequently used to optimize the operation of the existing or development of new equipment [7, 8]. A great advantage of CFD is a high num- ber of outputs, such as scalar and vector fields of physical quantities, or particle trajectories [9]. The current calculation methods are highly efficient, and the solution time is short. Thus, when compared with experimental solutions, the calculation methods are advantageous especially in terms of costs. Still, the output CFD simulations more or less differ from the reality as they work on the basis of simplified mathematical models of different physical phenomena (e.g. turbulence, burning, etc.) [10]. This article deals with verification of CFD simulation of the combustion process. 


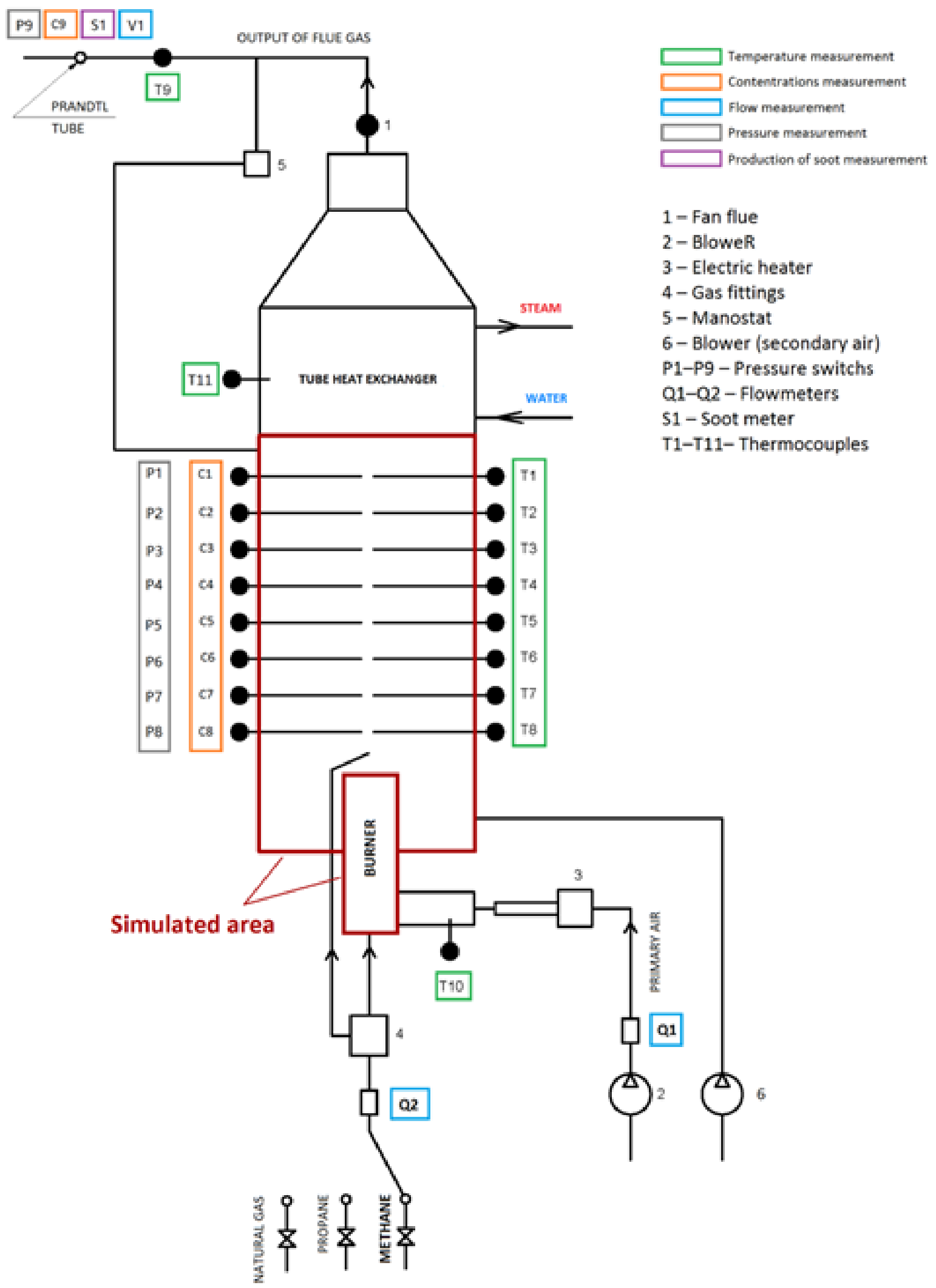

Fig. 1. Scheme of experimental combustion system 


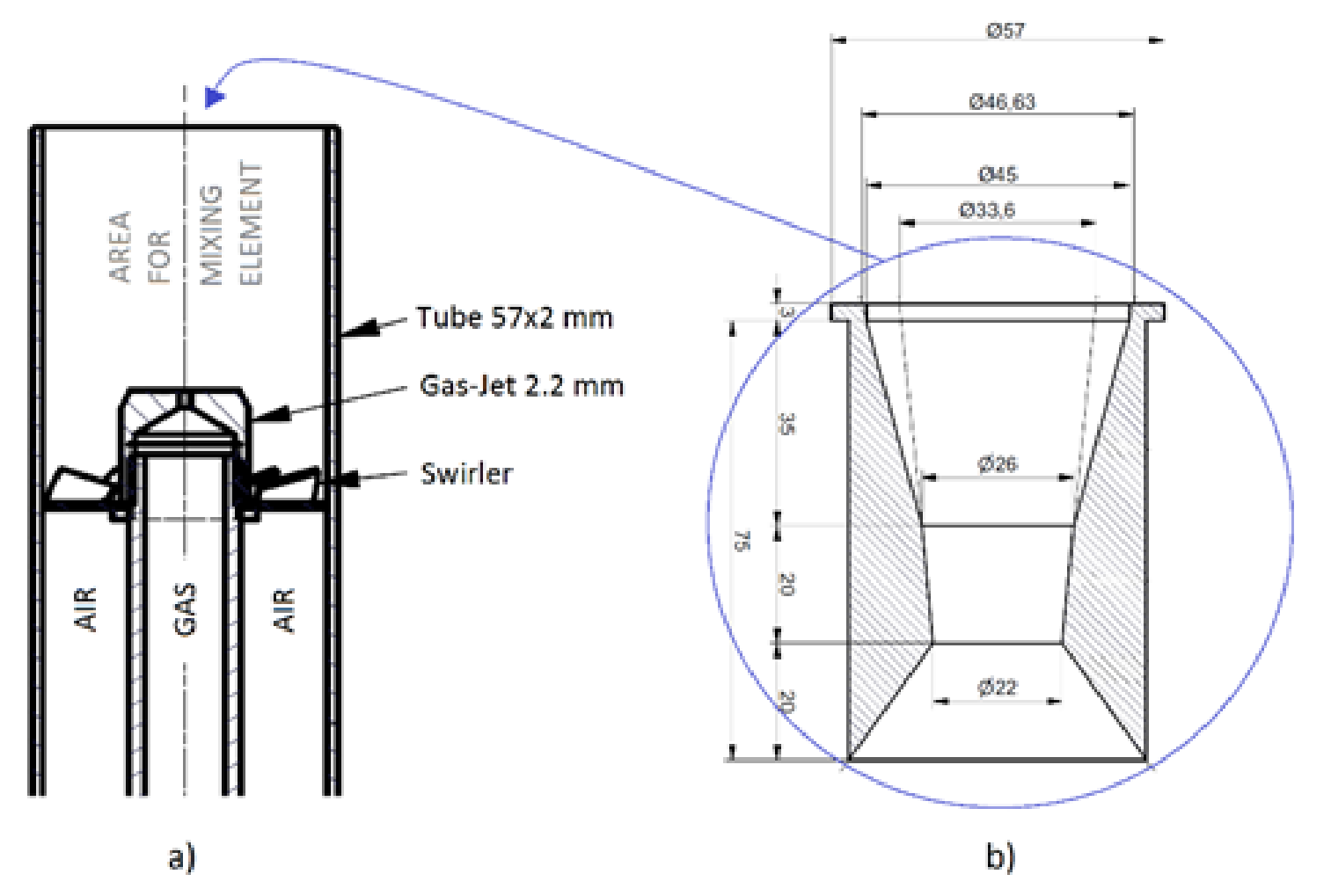

Fig. 2. a) burner without the mixing element, b) mixing element

Several authors have aimed to verify the prediction of mathematical models of combustion and related phenomena. For example, Yan et al. [11] compared the accuracy of final values of axial velocity and temperature of combustion products obtained via radiation simulations using Weighted-Sum-of-Gray-Gas (WSGG) and Efficient Exponential Wide Band (E-EWB). Natural gas was combusted in a chamber of $300 \mathrm{~kW}$ output. Tyliszczak et al. [12] compared the results rendered by flow models Reynolds Averaged Navier-Stokes (RANS) + k-epsilon and Large Eddy Simulation (LES) with experimentally obtained data (velocity, concentration of $\mathrm{CO}$ and $\mathrm{CO}_{2}$ ) from an industrial combustion chamber with a gas turbine. Andreini et al. [13] presented a study verifying CFD simulation of NOx production during the combustion of natural gas. They used a simple model of RANS flow and a model of turbulence k- $\varepsilon$. Mayr et al. [14] reported the results of CFD simulations of natural gas combustion using different percentages of $\mathrm{O}_{2} / \mathrm{N}_{2}$ with regard to the thermal field and heat flows into the chamber walls. The simulations were verified via experimental measurements in a laboratory furnace of 28-115 kW output. Turbulence was simulated using Reynolds-averaged Navier-Stokes equa- tions (RANS) and k-e, while heat transfer via radiation was simulated using Discrete Ordinary (DO) method. Gómez et al. [15] presented CFD Eulerian transient model for biomass combustion in a $60 \mathrm{~kW}$ pellet boiler. The accuracy of the mathematical simulation predictions was verified via the measurements of combustion product temperature and $\mathrm{CO}$ and $\mathrm{CO}_{2}$ concentrations at the boiler outlet.

This article focuses on the mathematical simulation of $\mathrm{CO}$ concentration, radiation intensity and thermal field in the conditions of a laboratory combustion chamber, which is at the bottom equipped with a vertical low-pressure, $\mathrm{CH}_{4}$ prototype burner of $4 \mathrm{~kW}$ output. The burner is also equipped with air baffle to optimize the flow field and so-called "mixing element" to intensify air and $\mathrm{CH}_{4}$ mixing. The final simulations are obtained having combined the mathematical models of Eddy Dissipation (for diffuse combustion), Discrete Transfer (for radiation) and $\mathrm{k}-\varepsilon$ (for turbulence) making use of CFX software. The aim of the article is to discuss to what extent the acquired results, having combined the stated models applied for the given prototype burner, are accurate. The results are verified via experimental measurements using a real model. 


\section{EXPERIMENTAL}

The simulated combustion chamber makes part of an experimental facility for the research and development of gas burners. The system is used to study the flame dynamics, kinetics of burning and heat transfer during combustion. The device is equipped with readers to measure pressure, temperature, flow rate and concentrations of combustion gas components. See Figure 1 for the scheme of the chamber, where the combustion space (red in the figure) has the following dimensions $0.5 \times 0.5 \times 1.0 \mathrm{~m}$. The walls are made of silica glass due to optical diagnostics. An external flue gas analyser with electrochemical sensors is used to measure $\mathrm{CO}$ concentration in combustion chamber. Flue gases temperature measurement is ensured by NiCr-Ni (Ti) thermocouples.

The vertically placed burner is in Figure 2a. It is a low-pressure burner, which partially pre-mixes gas and air. As parts of the burner, Figure $2 b$ shows a mixing element to intensify the mixing of gas and air.

\section{BOUNDARY CONDITIONS AND OTHER INPUT VALUES FOR THE MATHEMATICAL MODEL}

In the course of the mathematical simulation as well as the experiment, the conditions were as follows. We combusted methane $\left(\mathrm{CH}_{4}\right)$ of $0.8 \times 10^{-4} \mathrm{~kg} \mathrm{~s}^{-1}$ flow - i.e. the burner output was $4 \mathrm{~kW}$. The flow rate of the combusted air (composition by weight was $23 \% \mathrm{O}_{2}$ and $77 \% \mathrm{~N}_{2}$ ) was $1.00 \times 10^{-3} \mathrm{~kg} \mathrm{~s}^{-1}$ The temperature of the fed $\mathrm{CH}_{4}$ and combustion air was $20^{\circ} \mathrm{C}$.

The turbulence intensity was set for the fed $\mathrm{CH}_{4}$ and combusted air to $10 \%$. The static pressure at the chamber outlet was $0 \mathrm{~Pa}$. The mean temperature of the walls was $77^{\circ} \mathrm{C}$ and emissivity was 1 .

The geometry of the simulated combustion chamber $(0.5 \times 0.5 \times 1.0 \mathrm{~m})$ was covered with a computational network of 465326 volume number. The network was thicker near the burner mouth and chamber walls, namely because of the big velocity and temperature gradients.

CFX software was used to create the computational network and for the subsequent experiment and result evaluation.

\section{DESCRIPTION OF THE APPLIED MATHEMATICAL MODELS}

Fluid flows were studied using averaged Navier-Stokes equations and continuity equations (see [16]). The thermal field was grounded in energy equation (see [17]) and the transport of the different combustion gas components issued from the mass balance (transport equations) (see [18]).

Turbulence was studied via $k-\varepsilon$ model. The basis of the model are two transport equations that deal with turbulent kinetic energy $k\left[\mathrm{~m}^{2} \mathrm{~s}^{-2}\right]$ and dissipation rate $\varepsilon\left[\mathrm{m}^{2} \mathrm{~s}^{-3}\right]$. Turbulent viscosity $\eta_{t}[\mathrm{~Pa} \mathrm{~s}]$ is herein defined as below:

$$
\eta_{t}=C_{\eta} \bar{\rho} \sqrt{k} L=C_{\eta} \bar{\rho} \frac{k^{2}}{\varepsilon}
$$

where $C \eta$ is an empirical coefficient, $L$ is a linear scale $[\mathrm{m}]$ and $\rho$ is density $\left[\mathrm{kg} \mathrm{m}^{-3}\right]$.

The equation for the turbulent energy transport is:

$$
\frac{\partial(\bar{\rho} k)}{\partial t}+\frac{\partial\left(\bar{\rho} \widetilde{U}_{j} k\right)}{\partial x_{j}}=P_{k}+\frac{\partial}{\partial x_{j}}\left[\left(\eta+\frac{\eta_{t}}{\sigma_{k}}\right) \frac{\partial k}{\partial x_{j}}\right]-\bar{\rho} \varepsilon
$$

and the model transport equation for the dissipation rate is expressed as below:

$$
\frac{\partial(\bar{\rho} \varepsilon)}{\partial t}+\frac{\partial\left(\bar{\rho} \widetilde{U}_{j} \varepsilon\right)}{\partial x_{j}}=\frac{\varepsilon}{k} C_{\varepsilon 1} P_{k}+\frac{\partial}{\partial x_{j}}\left[\left(\eta+\frac{\eta_{t}}{\sigma_{\varepsilon}}\right) \frac{\partial \varepsilon}{\partial x_{j}}\right]-\frac{\varepsilon}{k} C_{\varepsilon 2} \bar{\rho} \varepsilon
$$

where $U$ is the velocity vector $\left[\mathrm{m} \mathrm{s}^{-1}\right]$, $\mathrm{t}$ is time [s], $\mathrm{x}$ is direction [m], $P_{k}$ is the production of turbulent kinetic energy, $\eta$ is dynamic viscosity, and $C_{\varepsilon l}$ and $\sigma_{\varepsilon}$ are constants.

The rate of chemical reactions was calculated using Eddy Dissipation model, which is grounded in turbulent kinetic energy $k$ and dissipation $\varepsilon$. The production rate of $i R_{i}$ component in this model is expressed as below: 


$$
\begin{aligned}
& R_{i}=A \frac{\varepsilon}{k} \min \left(\frac{c_{i, R}}{v^{\prime}{ }_{i I}}\right)\left[\mathrm{kg} \cdot \mathrm{m}^{-3} \cdot \mathrm{s}^{-1}\right] \\
& R_{i}=A B \frac{\varepsilon}{k}\left(\frac{\sum_{P} c_{i, P} W_{I}}{\sum_{P} v^{\prime \prime}{ }_{i I} W_{I}}\right)\left[\mathrm{kg} \cdot \mathrm{m}^{-3} \cdot \mathrm{s}^{-1}\right]
\end{aligned}
$$

In Equations (4) and (5), $A$ and $B$ are empirical coefficients $[-], \varepsilon / k$ is the dissipation rate $\left[\mathrm{s}^{-1}\right]$, $c_{i, P}$ and $c_{i, R}$ are molar concentrations of the product and reactant, and $v_{i I}^{\prime}$ and $v_{i I}^{\prime \prime}$ are the stoichiometric coefficients of the product and the reactant. We always consider the lower value of $R_{i}$.

Thermal radiation in the combustion chamber was simulated via Discrete Transfer model. Its principle lies in the simulation of a certain number of rays that emit and absorb radiation energy - it is a model of radiation intensity $I\left[\mathrm{~W} \cdot \mathrm{m}^{-3}\right]$ change replaced by change in the trajectory $s[\mathrm{~m}]$ :

$$
\frac{d I}{d s}=-\bar{K}_{a} I+\bar{K}_{a} \frac{\sigma T^{4}}{\pi}
$$

where $K_{a}$ is the absorption coefficient $\left[\mathrm{m}^{-1}\right], T$ is temperature $[\mathrm{K}]$ and $\sigma$ is Stefan-Boltzmann constant $\left[\mathrm{W} \cdot \mathrm{m}^{-2} \mathrm{~K}^{-4}\right]$.

\section{RESULTS AND DISCUSSION}

This section presents the results of the mathematical models and of the real experimental measurements, and discusses the mutual differences.

\section{Thermal, vector and radiation fields}

Figure 3a shows the simulation of a thermal field at the level of combustion chamber symmetry. Combustion of methane $\left(\mathrm{CH}_{4}\right)$ in a diffuse regime occurs in the locations with the highest temperatures as at the inlet the mixture of $\mathrm{CH}_{4}$ and oxygen $\left(\mathrm{O}_{2}\right)$ is not pre-mixed. From the geometrical point of view, the flame may be divided into a pre-heating zone, flame zone and dumping zone. Because we chose a statistic model of turbulence k- $\varepsilon$ that considers averaged physical quantities, the flame boundary is relatively "smooth". The combination of mathematical models predicts that the combustion chamber has the maximum temperature of $1496{ }^{\circ} \mathrm{C}$.

Figure $3 \mathrm{~b}$ presents a thermally coloured vector field. For better clarity, we opted for an identical size of the vectors. It is obvious that the outlet flow from the burner mouth is gradually widening towards the side walls of the combustion chamber. Near the walls, a part of the combustion product flow changes its direction back to the bottom of the chamber and a circulation zone is forming. The visualisation implies that during the flow no circulations arise that would have a negative impact on the stability of the combustion process and cause a bad operation of the burner.

The final field of radiation intensity (RI) at the level of combustion chamber symmetry is shown in Figure 3c. Radiation is the most intense in the

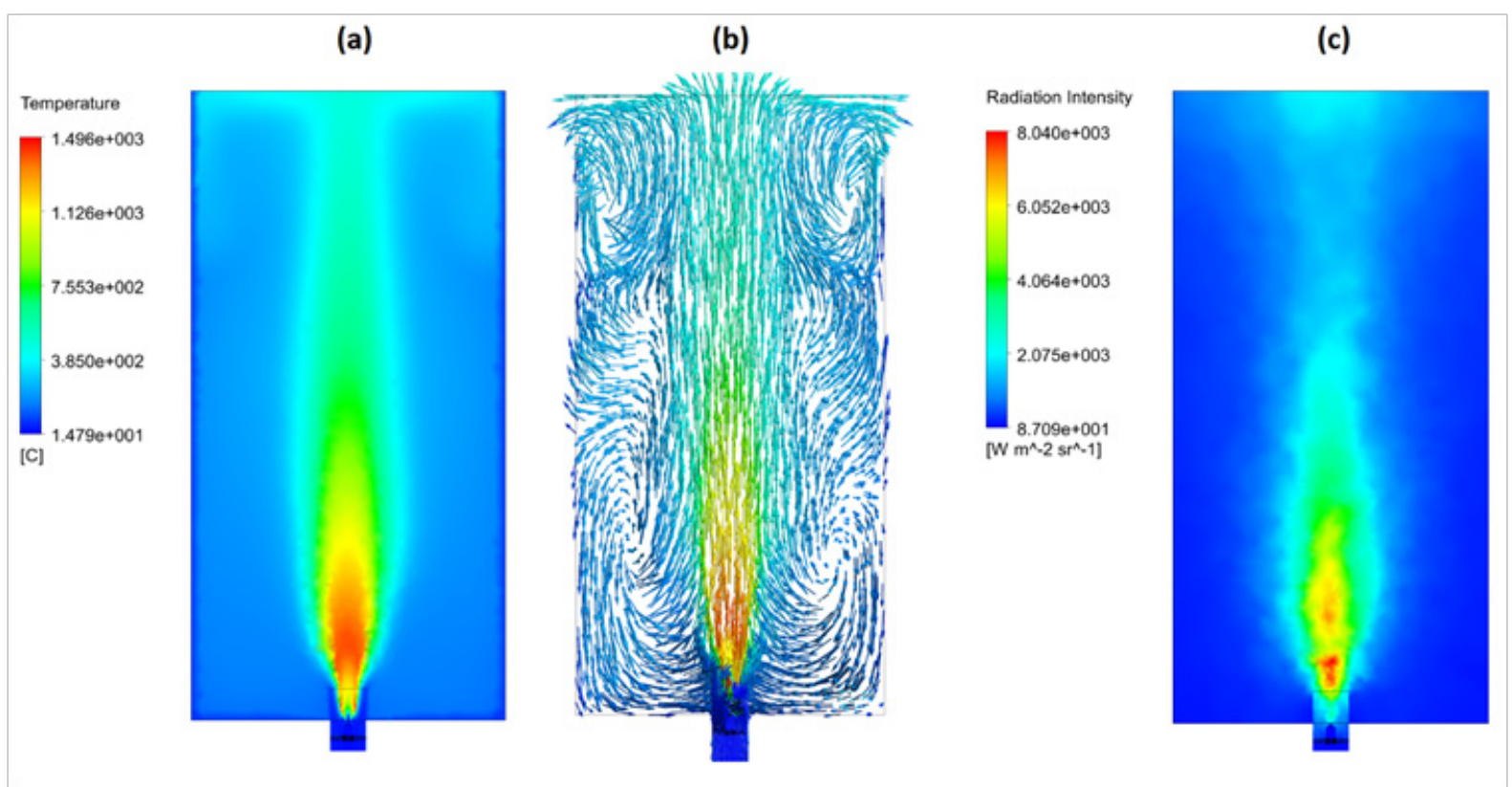

Fig. 3. a) thermal, b) vector, c) radiation fields at the level of combustion chamber symmetry 
flame area (maximum value of $8.151 \mathrm{~kW} \mathrm{~m}^{-2}$ $\mathrm{sr}^{-1}$ ), which correlates with the high temperatures in the section. The lowest RI values are reached near the combustion chamber bottom as there are lower temperatures and smaller concentrations of carbon dioxide and vapour, i.e. components that predominantly participate in the radiation of thermal energy of combustion products.

\section{Verification of mathematical simulations}

Note: It holds true for the following Figures 4 and 5 that the courses of the selected quantity values are plotted on the vertical axis of the combustion space, where the bottom is situated at the height of $0 \mathrm{~mm}$ and the outlet of the mixtures from the "mixing element" is situated at the level of $50 \mathrm{~mm}$. The geometry of the mixing element is shown in Figure 2 in Experimental Section.

Figure 4 compares the theoretical and real courses of temperature. It is clear that the mathematical temperature models slightly overestimate the values, where the mean deviation between the model and reality is $+21.7 \%$. Still, we cannot unambiguously say that the prediction accuracy is higher/lower in the higher temperature areas, or vice versa. In the localities with the highest temperatures (i.e. flame core - level of $94 \mathrm{~mm}$ ), the simulation differs by about $+12.7 \%$, and near the combustion product outlet (level of $658 \mathrm{~mm}$ ), the difference in the final temperature amounts to $+9.6 \%$.

The concentration of carbon monoxide (CO) is shown in Figure 5. The occurrence of $\mathrm{CO}$ is understandable as the mechanism of combustion of methane into carbon dioxide may be sim-

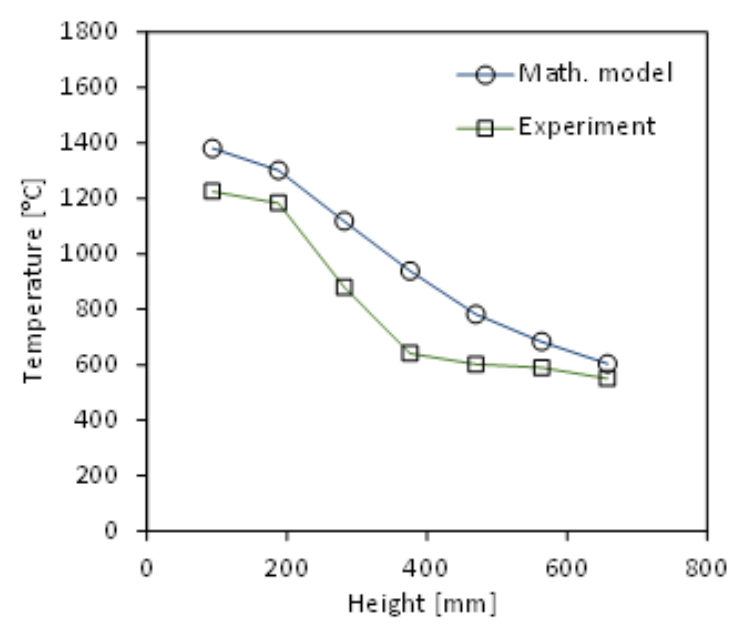

Fig. 4. Temperatures in the combustion chamber axis plified to: (i) $\mathrm{CH} 4+1.5 \mathrm{O}_{2} \rightarrow \mathrm{CO}+2 \mathrm{H}_{2} \mathrm{O}$, (ii) $\mathrm{CO}+0.5 \mathrm{O}_{2} \rightarrow \mathrm{CO}_{2}$. The concentration of $\mathrm{CO}$ falls along the height of the combustion chamber (from the burner mouth to combustion gas outlet), both in case of the theoretical results and real experiment results. With regard to the fact that reactant mixing on the molecular level is not immediate, the gradual lowering of $\mathrm{CO}$ is logical. Interesting are the differences between the real and predicted value of CO concentration as for the locality. While at the combustion chamber level of $97 \mathrm{~mm}$ the deviation from the predicted $\mathrm{CO}$ concentration was $-57.0 \%$, at the level of $188 \mathrm{~mm}$ the deviation was $+31.8 \%$. The real decrease in $\mathrm{CO}$ concentration was very sharp. The falling trend in the theoretical model was "more moderate". This implies that the applied model Eddy Dissipation is in our case not too much suitable for the prediction of $\mathrm{CO}$ concentrations in the areas of big concentration gradients (in flame core), even despite the fact that diffuse combustion was simulated.

The major causes of the above stated deviations between the theoretical values and the real ones could be explained by:

- the set constant temperature and the emissivity of the combustion chamber walls,

- non-stationarity of the simulated phenomena is not considered,

- the applied model of turbulence is more accurate in cases of fully developed turbulence, which does not occur in all the parts of the combustion chamber, and (iv) the experimental measurements are always burdened by a certain error.

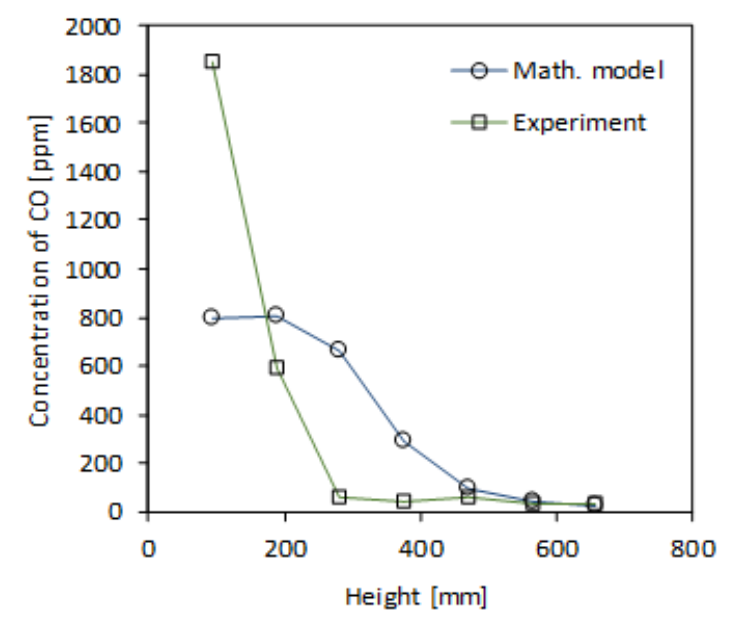

Fig. 5. Contrentations of $\mathrm{CO}$ in the combustion chamber axis 


\section{CONCLUSIONS}

The article verifies the accuracy of combustion chamber simulations obtained via combining the models of Eddy Dissipation, $k-\varepsilon$ and Discrete Transfer. The specific aspect of the research lies in the prototype burner equipped with an air baffle and the so-called mixing element. The mixing element is placed vertically in the lower section of the simulated combustion chamber. Methane was combusted in the burner, the output was $4 \mathrm{~kW}$.

The results imply that the application of the stated models to simulate the temperature courses along the combustion chamber height is suitable. The verification measurements imply that the mean deviation was $+21.7 \%$. At the level of the combustion gas outlet from the combustion chamber, the theoretical temperature differs from the real temperature by only $+9.6 \%$. The simulation of CO concentration in the combustion chamber shows a significant difference in the area of flame. While the theoretical value of CO concentration was $797 \mathrm{ppm}$, the real value was $1852 \mathrm{ppm}$. In areas of lower temperatures, the theoretical results were much more satisfactory. We may thus deduce that the applied Eddy Dissipation (in combination with other models) model (in combination with other models) of diffuse combustion significantly underestimates the $\mathrm{CO}$ concentration as for the areas of high concentrations. The follow-up research will focus on better accuracy of the predictions via the application of complementary models of the kinetics of burning.

Taking into account the physical-chemical complexity of the combustion process, we may consider the deviations in the stated mathematical models as acceptable. We may conclude that the method predicts the course of selected physical phenomena in a satisfactory manner and it is applicable for analogous tasks.

\section{Acknowledgements}

This study was conducted within the framework of the projects LO1404: Sustainable Development of the ENET Centre, CZ.1.05/2.1.00/19.0389: Research Infrastructure Development of the CENET, SP2017/72: Research on combustion of alternative fuels in the fluidized bed, and CZ.01.1.02/0.0/0.0/15_019/00 04771: Torrefaction.

\section{REFERENCES}

1. Honus, S., Bocko, P., Bouda, T., Ristović, I., Vulić, M.: The effect of the number of conveyor belt carrying idlers on the failure of an impact place: A failure analysis. Eng. Fail. Anal., 77, 2017, 93-101.

2. Rozylo, P., Teter, A., Debski, H., Wysmulski, P., Falkowicz, K.: Experimental and Numerical Study of the Buckling of Composite Profiles with Open Cross Section under Axial Compression. Appl. Compos. Mater. 24, 2017, 1251-1264.

3. Stanova, E., Fedorko, G., Kmet, S., Molnar, V., Fabian, M.: Finite element analysis of spiral strands with different shapes subjected to axial loads. Adv. Eng. Softw. 83, 2015, 45-58.

4. Gajdos, I., Slota, J., Spisak, E., Jachowicz, T., TorSwiatek, A.: Structure and tensile properties evaluation of samples produced by Fused Deposition Modeling. Open Eng. 6, 2016, 86-89.

5. Baleta, J., Mikulčić, H., Vujanović, M., Petranović, Z., Duić, N.: Numerical simulation of urea based selective non-catalytic reduction deNOx process for industrial applications. Energy Convers. Manag. 125, 2016, 59-69.

6. Mikulčić, H., von Berg, E., Vujanović, M., Wang, X., Tan, H., Duić, N.: Numerical evaluation of different pulverized coal and solid recovered fuel cofiring modes inside a large-scale cement calciner. Appl. Energy. 184, 2016, 1292-1305.

7. Andersson, B., Andersson, R., Hakansson, L., Mortensen, M.: Computational Fluid Dynamics for Engineers. Cambridge University Press, 2012, 202 pages.

8. Pletcher, T.H., Tannehill, J.C., Anderson, D.: Computational Fluid Mechanics and Heat Transfer. Taylor \& Francis, 2011.

9. Pozrikidis, C.: Introduction to Theoretical and Computational Fluid Dynamics. Oxford University Press, 2011.

10. Yeoh, G.H., Yuen, K.K.: Computational Fluid Dynamics in Fire Engineering: Theory, Modelling and Practice. Butterworth-Heinemann, 2009.

11. Yan, L., Yue, G., He, B.: Application of an efficient exponential wide band model for the natural gas combustion simulation in a $300 \mathrm{~kW}$ BERL burner furnace. Appl. Therm. Eng. 94, 2016, 209-220.

12. Tyliszczak, A., Boguslawski, A., Nowak, D.: Numerical simulations of combustion process in a gas turbine with a single and multi-point fuel injection system. Appl. Energy. 174, 2016, 153-165.

13. Andreini, A., Cerutti, M., Facchini, B., Innocenti, A.: CFD analysis of NOx emissions of a natural 
gas lean premixed burner for heavy duty gas turbine. In: Energy Procedia. 81, 2015, 967-976.

14. Mayr, B., Prieler, R., Demuth, M., Potesser, M., Hochenauer, C.: CFD and experimental analysis of a $115 \mathrm{~kW}$ natural gas fired lab-scale furnace under oxy-fuel and air-fuel conditions. Fuel. 159, 2015, 864-875.

15. Gómez, M.A., Porteiro, J., Patiño, D., Míguez, J.L.: Eulerian CFD modelling for biomass com- bustion. Transient simulation of an underfeed pellet boiler. Energy Convers. Manag. 101, 2015, 666-680.

16. Př́hoda, J., Louda, P.: Matematické modelování turbulentního proudění. CVUT Prague, 2007.

17. ANSYS CFX-Solver Theory Guide. ANSYS, Inc., 2009.

18. Jelemenský, K., Šesták, J., Žitný, R.: Tepelné pochody. STU Bratislava, 2000. 